\title{
Diagnosis, assessment, and phenotyping of COPD: beyond FEV,
}

\author{
This article was published in the following Dove Press journal: \\ International Journal of COPD \\ 19 February 2016 \\ Number of times this article has been viewed
}

\author{
Peter Lange ${ }^{1,2}$ \\ David M Halpin ${ }^{3}$ \\ Denis E O'Donnell ${ }^{4}$ \\ William MacNee ${ }^{5}$ \\ 'Respiratory Section, Hvidovre \\ Hospital, Copenhagen, Denmark; \\ ${ }^{2}$ Department of Health, University of \\ Copenhagen, Copenhagen, Denmark; \\ ${ }^{3}$ Royal Devon and Exeter Hospital, \\ Exeter, UK; ${ }^{4}$ Respiratory Investigation \\ Unit, Queen's University and \\ Kingston General Hospital, Kingston, \\ ON, Canada; ${ }^{5}$ MRC Centre for \\ Inflammation Research, The Queen's \\ Medical Research Institute, University \\ of Edinburgh, Edinburgh, UK
}

Correspondence: Peter Lange

Respiratory Section, Hvidovre Hospital, Kettegård Allé 30

2650 Hvidovre, Copenhagen, Denmark

Tel +453532 7984

Fax +45 26879020

Email peter.lange@sund.ku.dk

\begin{abstract}
COPD is now widely recognized as a complex heterogeneous syndrome, having both pulmonary and extrapulmonary features. In clinical practice, the diagnosis of COPD is based on the presence of chronic airflow limitation, as assessed by post-bronchodilator spirometry. The severity of the airflow limitation, as measured by percent predicted $\mathrm{FEV}_{1}$, provides important information to the physician to enable optimization of management. However, in order to accurately assess the complexity of COPD, there need to be other measures made beyond $\mathrm{FEV}_{1}$. At present, there is a lack of reliable and simple blood biomarkers to confirm and further assess the diagnosis of COPD. However, it is possible to identify patients who display different phenotypic characteristics of COPD that relate to clinically relevant outcomes. Currently, validated phenotypes of COPD include alpha-1 antitrypsin deficiency, and "frequent exacerbators". Recently, a definition and assessment of a new phenotype comprising patients with overlapping features of asthma and COPD has been suggested and is known as "asthma COPD overlap syndrome". Several other phenotypes have been proposed, but require validation against clinical outcomes. Defining phenotypes requires the assessment of multiple factors indicating disease severity, its impact, and its activity. Recognition and validation of COPD phenotypes has an important role to play in the selection of evidence-based targeted therapy in the future management of COPD, but regardless of the diagnostic terms, patients with COPD should be assessed and treated according to their individual treatable characteristics.
\end{abstract}

Keywords: COPD, asthma, ACOS, phenotype, diagnosis

\section{Introduction}

COPD is now widely recognized as a complex heterogeneous syndrome with pulmonary and extrapulmonary features. ${ }^{1,2}$ In the assessment of patients with COPD, it is important to identify clinical traits or phenotypes that may have consequences for the choice of treatment. ${ }^{1,3}$

The aim of this article is to discuss the challenges of accurately diagnosing and assessing COPD, to present the evidence for the importance of defining COPD phenotypes, and to provide guidance on how these phenotypes could be assessed. Rather than presenting a systematic review of the literature, we aim to debate and discuss the current status of COPD diagnosis, the proposed COPD phenotypes, and the difficulties and relevance of differentiating between asthma, COPD, and asthma COPD overlap syndrome (ACOS).

\section{Importance of a correct diagnosis}

An accurate diagnosis guides the physician to identify the most appropriate management strategy. In particular, assessment of symptoms in asthma, COPD, and ACOS is crucial to achieving an accurate diagnosis.

International Journal of COPD 2016:II (Special Issue Ist World Lung Disease Summit) 3-12 3

Dovepress

http://dx.doi.org/10.2147/COPD.S85976 (c) (1) (5) 2016 Lange et al. This work is published by Dove Medical Press Limited, and licensed under Creative Commons Attribution - Non Commercial (unported, v3.0) (c) Le ${ }_{\mathrm{BY}} \mathrm{NC}$ License. The full terms of the License are available at http://creativecommons.org/licenses/by-nc/3.0/. Non-commercial uses of the work are permitted without any further permission from Dove Medical Press Limited, provided the work is properly attributed. Permissions beyond the scope of the License are administered by Dove Medical Press Limited. Information on how to request permission may be found at: http://www.dovepress.com/permissions.php 
Prior to diagnosis, many patients with COPD may not recognize their symptoms as being due to a disease, since breathlessness may be attributed to aging, and cough and sputum production may be considered a consequence of smoking. An accurate diagnosis may help patients accept that they have COPD and to take action to change their lifestyle and help manage their symptoms. ${ }^{4}$

\section{How to diagnose COPD}

According to the most recent Global initiative for chronic Obstructive Lung Disease (GOLD) strategy for diagnosis and management of COPD, a diagnosis of COPD should be considered in any patient with symptoms of dyspnea, chronic cough or sputum production, and a history of risk factors for COPD (particularly tobacco smoking). Spirometry is mandatory to confirm the presence of persistent airflow limitation, a defining, but not a pathognomonic characteristic of COPD.

\section{FEV}

The standard diagnostic definition of persistent airflow limitation is a post-bronchodilator ratio of forced expiratory volume in 1 second to forced vital capacity $\left(\mathrm{FEV}_{1} /\right.$ FVC) of $<0.7 .^{2}$ However, this definition will underestimate the presence of COPD in younger patients and overestimate its presence in older patients, in whom airflow limitation may simply be a result of advancing age. ${ }^{5,6}$ This is especially true for mild disease, where $75 \%$ of patients aged $>65$ years and meeting the GOLD 1 criteria for airflow limitation have been shown to have $\mathrm{FEV}_{1} / \mathrm{FVC}$ values that lie within the normal range for healthy age-related and race-matched controls. ${ }^{5}$ Establishing the lower limit of "normal" is highly dependent on the reference population and has not been validated in longitudinal studies. Thus, due to its simplicity and validation in many studies, the fixed $\mathrm{FEV}_{1} / \mathrm{FVC}$ ratio has remained the diagnostic criterion for the clinical situation, whereas the lower limit of normal has been advocated for use in epidemiological studies.

\section{Beyond FEV,}

In an effort to improve the management of patients with COPD and encourage a more comprehensive assessment of patients, the GOLD guidelines were revised recently to include COPD categories based on a combined score for symptoms, degree of airflow limitation, risk of exacerbation, and presence of comorbidities (Table 1). ${ }^{2}$ However, comprehensive assessment in order to obtain a better understanding of the symptomatology in an individual patient should also include other parameters.

\section{Resting inspiratory capacity}

One of the functional consequences of the pathological changes that occur in COPD is over-inflation of the lungs. ${ }^{7}$ Resting inspiratory capacity (IC) is an indirect but very powerful and non-invasive measure of lung hyperinflation, and of the elastic load being exerted on the inspiratory muscles. IC decreases linearly with increasing airflow limitation ${ }^{8}$ and is sufficiently sensitive to signal airway obstruction even in mild disease when $\mathrm{FEV}_{1}$ is largely unaffected. Resting IC is considered a good indicator of the severity of COPD and, as a ratio with total lung capacity (TLC), predicts mortality and respiratory failure. ${ }^{9}$

During exercise in patients with COPD, end expiratory lung volume increases, IC and inspiratory reserve volume (IRV) both diminish, and further tidal volume expansion is limited as TLC is approached (Figure 1). In advanced COPD, the low IC means that the IRV reaches its minimal value $(\sim 0.5 \mathrm{~L}$

Table I COPD categories based on a combined score for symptoms, degree of airflow limitation, exacerbation risk, and presence of comorbidities

\begin{tabular}{llllll}
\hline Patient & Characteristic & $\begin{array}{l}\text { Spirometric } \\
\text { classification }\end{array}$ & $\begin{array}{l}\text { Exacerbations } \\
\text { per year }\end{array}$ & $\begin{array}{l}\text { COPD Assessment } \\
\text { Test }\end{array}$ & mMRC score \\
\hline A & $\begin{array}{l}\text { Low risk, } \\
\text { less symptoms } \\
\text { Low risk, } \\
\text { more symptoms }\end{array}$ & GOLD I-2 & $\leq 1^{\mathrm{a}}$ & $<10$ & $0-1$ \\
B & $\begin{array}{l}\text { High risk, } \\
\text { less symptoms }\end{array}$ & GOLD 3-4 $1-2$ & $\leq 1^{\mathrm{a}}$ & $\geq 10$ & 02 \\
C & $\begin{array}{l}\text { High risk, } \\
\text { more symptoms }\end{array}$ & GOLD 3-4 & $\geq 2^{\mathrm{b}}$ & $<10$ & $\geq 1$ \\
D & & $\geq 2^{\mathrm{b}}$ & $\geq 10$ & $\geq 2$ \\
\hline
\end{tabular}

Notes: GOLD I-2, mild-moderate airflow limitation; GOLD 3-4, severe-very severe airflow limitation; ${ }^{a}$ not leading to hospital admission; ${ }^{b} \geq$ I leading to hospital admission. From the Global Strategy for Diagnosis, Management and Prevention of COPD 2015, (c) Global Initiative for Chronic Obstructive Lung Disease (GOLD), all rights reserved. Available from http://www.goldcopd.org. ${ }^{2}$

Abbreviations: GOLD, Global initiative for chronic Obstructive Lung Disease; mMRC, modified Medical Research Council. 

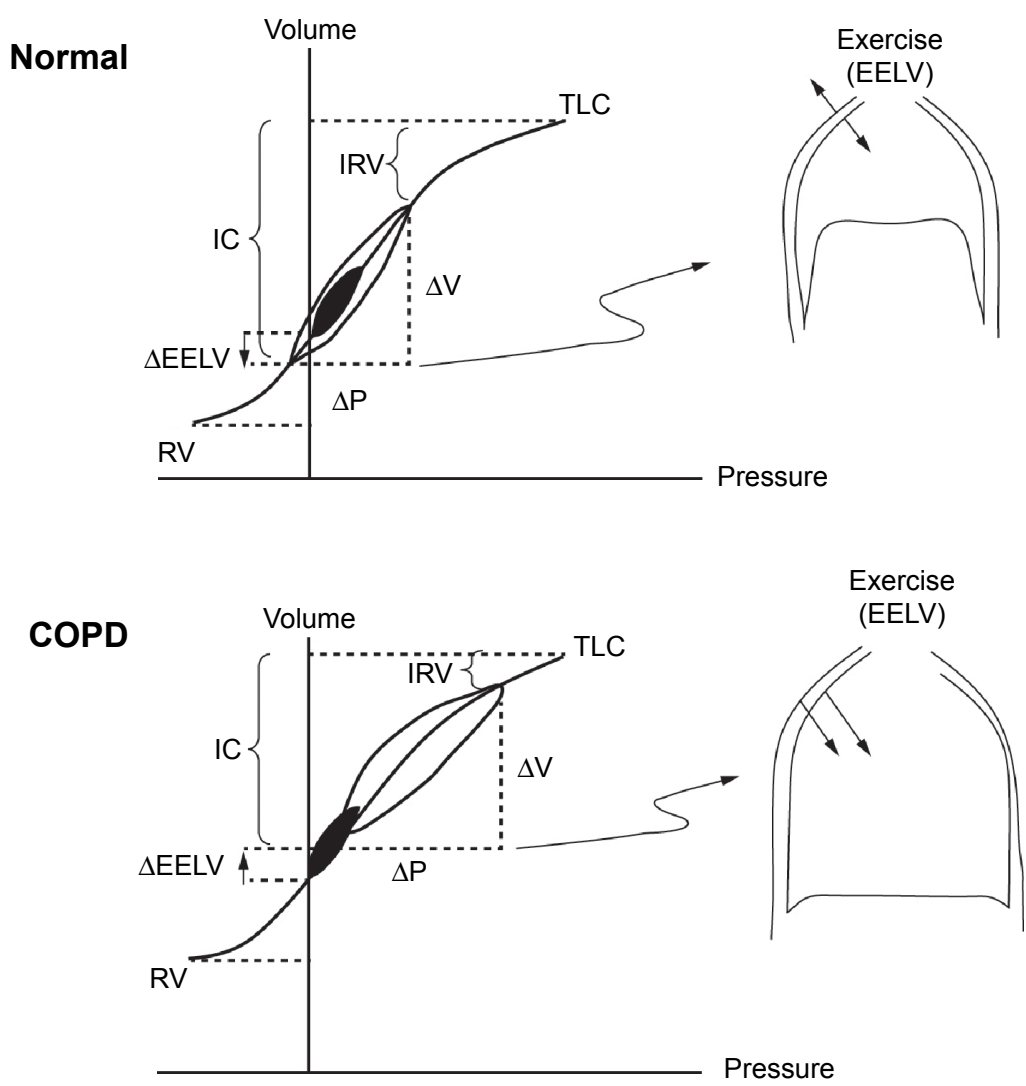

Figure I Comparison of pulmonary dynamics in health and COPD showing tidal pressure-volume curves during rest (filled area) and exercise (open area). Notes: Reproduced with permission of Taylor \& Francis Ltd (http://www.tandfonline.com). O'Donnell DE, Laveneziana P. The clinical importance of dynamic lung hyperinflation in COPD. COPD: Journal of Chronic Obstructive Pulmonary Disease. 2006;3(4):219-232. ${ }^{79}$

Abbreviations: EELV, end-expiratory lung volume; IC, inspiratory capacity; IRV, inspiratory reserve volume; P, pressure; RV, residual volume; TLC, total lung capacity; $\mathrm{V}$, volume.

below TLC) at low exercise intensities; further increases in ventilation become impossible and exercise is terminated. During exercise, the central drive to breathe continues to increase, but the ability of the respiratory muscles to respond to this drive progressively diminishes because of the effects of dynamic lung hyperinflation (critical reduction in IRV). It follows that a much greater respiratory effort is required to generate the same tidal volume as at rest, thereby leading to intolerable shortness of breath. IC at rest is therefore a good predictor of maximal ventilatory capacity and a patient's ability to exercise. Increasing IC with bronchodilators is associated with reduced dyspnea ratings and improved exercise tolerance. ${ }^{10}$

\section{Field and laboratory exercise tests}

The impact of COPD on a patient's functional capacity in relation to exercise can be explored using the 6-minute walking distance (6MWD) test. This test is simple to perform, correlates well with peak oxygen uptake, and is a good index of functional disability. It relates to daily activities and has predictive value in relation to health status and survival, but not hospitalizations for COPD exacerbations. ${ }^{11-13}$ The shuttle walking test is an alternative to the $6 \mathrm{MWD}$ test and is perhaps more responsive to the effect of training. ${ }^{14}$

Another method of measuring the functional impact of COPD is to use cardiopulmonary exercise testing. This requires more equipment than other field tests, and provides a measure of the integrated function of the respiratory, cardiocirculatory, peripheral muscle, and neurosensory systems under stress. It accurately quantifies abnormalities in pulmonary gas exchange, ventilatory demand, and dynamic respiratory mechanics and their sensory consequences. Furthermore, peak oxygen uptake measured during incremental exercise tests has prognostic value in relation to survival in COPD. ${ }^{15}$

\section{Chest computed tomography scanning}

Thoracic computed tomography (CT) scanning can be used to quantify the extent, type, distribution, and progression of emphysema; ${ }^{16,17}$ however, measurement of airway dimensions using $\mathrm{CT}$ scanning has been more problematic. ${ }^{18,19}$ 
The presence of emphysema is associated with a more rapid decline in $\mathrm{FEV}_{1}$ and with increased mortality, ${ }^{20}$ and recent studies have shown relationships between both the extent of emphysema and airway thickening and the frequency of exacerbations. ${ }^{21-23}$ The distribution of emphysema has also been used to define a COPD phenotype, ie, upper lobe heterogeneous emphysema, as a clinical trait that shows improvement in survival with lung volume reduction surgery. ${ }^{24}$ In addition, chest $\mathrm{CT}$ scanning can aid the diagnosis of other lung conditions, such as bronchiectasis, obliterative bronchiolitis, and diffuse panbronchiolitis, ${ }^{2,6}$ and can be used to assess comorbidities such as coronary artery disease by measuring coronary artery calcification. ${ }^{25} \mathrm{CT}$ scans have also proven useful for identifying patients with a mixed asthma/ COPD phenotype who have airway-predominant symptoms (as opposed to emphysema-predominant symptoms) and features of asthma. ${ }^{26}$

\section{COPD phenotypes}

The concept of a clinical COPD phenotype has been proposed as

a single or combination of disease attributes that describe differences between individuals with COPD as they relate to clinically meaningful outcomes like symptoms, exacerbations, response to therapy, rate of disease progression, or death. ${ }^{1}$

The goal of COPD phenotyping is to be able to classify patients into distinct subgroups according to prognosis and response to therapy in order to better select the appropriate therapy that can optimize clinically meaningful outcomes for patients.

\section{What phenotypes have been proposed?}

The ECLIPSE study of 2,164 patients with COPD has helped to expand our knowledge of several COPD phenotypes and identified potential biomarkers for predicting clinical outcomes in these phenotypes. $^{27}$

Prospective validation of COPD phenotypes against clinical outcomes or response to treatment is essential in defining a phenotype. ${ }^{1}$ At least three COPD phenotypes have been validated in this way. Alpha- 1 antitrypsin deficiency is a genetic condition that predisposes patients to COPD and liver disease, and has been identified as a specific phenotype that may respond positively to augmentation therapy. ${ }^{28}$

A second validated phenotype, emphysema/hyperinflation, characterized by upper-lobe emphysema, dyspnea, and poor exercise capacity, is associated with severe airflow limitation.
This phenotype appears to respond well to lung volume reduction surgery, which improves survival. ${ }^{24,29}$

Frequent exacerbators ( $\geq 2$ per year), a third phenotype, have poor quality of life, increased mortality, and a greater decline in lung function. ${ }^{11,27,30}$ This phenotype is also associated with high risk for gastroesophageal reflux disease and elevated white blood cell counts. Therapies that reduce the frequency of exacerbations are available and they also improve quality of life in this phenotype. ${ }^{31}$ On average, frequent exacerbators have more severe airway obstruction, with significantly higher values for the modified Medical Research Council dyspnea scale and increased Body mass index, airflow Obstruction, Dyspnea and Exercise (BODE) index compared with infrequent exacerbators. ${ }^{32,33}$

Several other potential phenotypes have been proposed, but are not yet fully validated against clinical outcomes. These include a phenotype of mild airway obstruction but disproportionately severe dyspnea; these patients may be detectable using tests for exercise performance and radiographic imaging. ${ }^{34,35}$ A phenotype of rapid lung function decline has also been described, which appears to be independently associated with severity of emphysema, as assessed by either CT or carbon monoxide transfer capacity. ${ }^{20,36}$ Other phenotypes associated with poor prognoses, including increased mortality, have been reported, ie, a phenotype with comorbidities linked to poor outcomes (eg, heart disease, systemic and vascular disease, and anxiety and depressive disorders $)^{37,38}$ and a phenotype with persistent inflammation, defined by ongoing elevation of blood inflammatory markers such as C-reactive protein, fibrinogen, and white blood cell count. ${ }^{39,40}$ The chronic bronchitis phenotype is also associated with poor outcomes. Compared with patients without chronic bronchitis, patients with this phenotype are more likely to be younger, male, Caucasian, have a greater extent of dyspnea, higher frequency of exacerbations, greater airway obstruction, and increased airway wall thickening, detectable both clinically and radiologically. ${ }^{41}$ This phenotype is also associated with a greater prevalence of cardiovascular comorbidities and sleep apnea syndrome than the emphysema and mixed asthma/COPD phenotypes. ${ }^{42}$

There are reports of a subgroup of COPD patients with chronic bacterial airway colonization who are at increased risk for frequent exacerbations, have higher levels of both airway and systemic inflammation, and are at increased risk of cardiovascular complications compared with those without chronic bacterial airway colonization. ${ }^{43}$

Some phenotypes describe COPD co-existing with other conditions. In the COPD/lung cancer phenotype, COPD 
increases the risk for lung cancer, and patients with COPD at the time of lung cancer diagnosis have a poorer prognosis than those with lung cancer and no COPD. ${ }^{44}$

Patients with COPD may develop pulmonary hypertension, which is usually mild, but a specific phenotype with severe pulmonary hypertension disproportionate to the underlying COPD has been proposed. ${ }^{45,46}$ This phenotype is characterized by diffuse emphysema on high-resolution CT scans, severe precapillary pulmonary hypertension ( $\geq 40 \mathrm{mmHg}$ ), severely reduced carbon monoxide diffusion capacity, progressive dyspnea, and normal spirometry. ${ }^{46,47}$

A subgroup of patients with COPD has been identified as non-smokers who may have developed COPD following exposure to dust and fumes not related to smoking. These individuals are at greater risk for pneumonia but have no additional risk for cardiovascular comorbidities or all-cause mortality compared with non-smokers without airway obstruction. ${ }^{48}$

Although the overlap of symptoms between asthma and COPD has been recognized for many years, its characterization as a separate phenotype has recently attracted much interest due to the publication of a consensus statement by Global Initiative for Asthma (GINA) and GOLD on the diagnosis, assessment, and treatment of this condition. ${ }^{49}$ This phenotype is discussed in detail in the following section.

\section{Differences between COPD and asthma \\ Key pathological and clinical differences}

In many patients, asthma and COPD have typical clinical features that usually make the two diseases distinguishable. The clinical features of COPD are reduced lung function, with limited reversibility, emphysema, and sometimes cor pulmonale and hypoxemia. Patients usually have a smoking history of many pack-years..$^{50}$ In contrast, asthma is characterized in the majority of patients by lung function that can be normalized through good response to therapy, and can often be associated with atopy, rhinitis, and high exhaled nitric oxide. ${ }^{49,51}$

Although guidelines ${ }^{2,49}$ define both asthma and COPD as inflammatory disorders of the respiratory system, distinct inflammatory patterns exist, driven by different chemical mediators. A key histopathological difference is the destruction of alveolar walls in COPD that leads to emphysema. ${ }^{52}$ Furthermore, the inflammation in the lungs is usually different in both diseases; $\mathrm{CD}^{+} \mathrm{T}$ cells and eosinophils are the predominant cells in asthma, while $\mathrm{CD} 8^{+} \mathrm{T}$ cells and neutrophils predominate in COPD. ${ }^{52}$ However, there is a greater difference between the cellular profiles of either of these conditions compared with healthy individuals than between the profiles seen in asthma and COPD (Figure 2)..$^{52-54}$

While smoking is a key driver of lung function decline in COPD, ${ }^{27}$ allergens are the main protagonists in asthma; however, smoking also accelerates lung function decline in asthma. ${ }^{55}$ A multivariate analysis of individuals with asthma found a dose-response relationship between smoking and lung function decline, but a greater effect of the presence versus the absence of airway hyper-reactivity. ${ }^{56}$

\section{Distinct phenotypes in asthma and COPD}

Several COPD phenotypes based on predominant symptoms have been described in this article and specific interventions are available to improve patient outcomes. ${ }^{1}$ Distinct asthma phenotypes have also been characterized on the basis of allergic status, the predominance of neutrophilic inflammation, late onset and persistent but reversible airflow limitation, degree of airway obstruction, atopic burden, and exacerbation history. ${ }^{57,58}$ These asthma phenotypes are distinguishable on the basis of clinical attributes, such as the type and severity of symptoms, and appear to respond to therapy differently, but consistently within phenotypes. ${ }^{57,58}$ However, it must be borne in mind that theoretical phenotypes are not always mirrored in practice; patients with COPD are not only heterogeneous but also complex, and different clinical characteristics or phenotypes may occur in any given patient. Thus, a range of treatable traits may occur in an individual COPD patient. ${ }^{59}$

\section{Similarities between asthma and COPD}

\section{Clinical and pathological similarities}

Asthma and COPD are both inflammatory lung disorders that result in airflow limitation. In particular, tackling a diagnosis that differentiates asthma from COPD is sometimes challenging because they share many clinical and pathological similarities (Table 2). ${ }^{2,49,60,61}$ In addition, ACOS may cause further diagnostic difficulties since the clinical aspects of this overlap population are not well understood. ${ }^{49,61-63}$ Consequently, unless it is clear from the patient history, a differential diagnosis with asthma may be difficult given that there is currently no single physiological test that can distinguish asthma and COPD. ${ }^{2}$

\section{Etiology}

According to the "Dutch hypothesis", asthma and COPD share a genetic basis, the expression of which is dependent on external factors such as age, sex, and environmental 

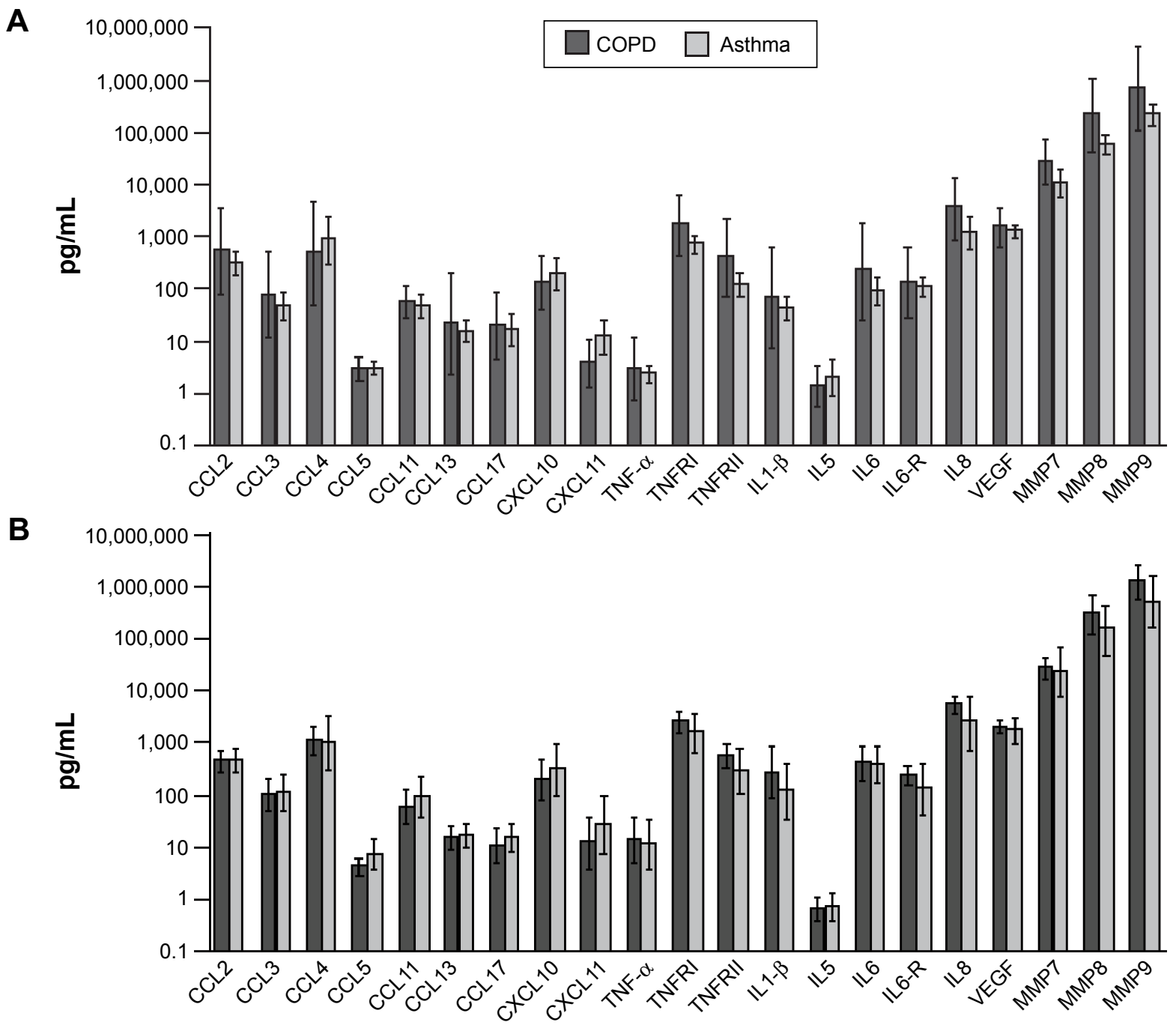

Figure 2 Sputum inflammatory mediators in patients with asthma and COPD having phenotypes for (A) eosinophilic airway inflammation and (B) non-eosinophilic airway inflammation. Horizontal and error bars set at geometric mean and $95 \%$ confidence interval.

Notes: Reproduced with permission from S. Karger AG, Basel, Switzerland. Copyright @ 2012 Bafadhel M, McCormick M, Saha S, et al. Profiling of sputum inflammatory mediators in asthma and chronic obstructive pulmonary disease. Respiration. 20I2;83(I):36-44. ${ }^{53}$

Abbreviations: CCL, CC chemokine ligand; CXCL, CXC chemokine ligand; IL, interleukin; MMP, matrix metallopeptidase; TNF, tumor necrosis factor; TNFR, tumor necrosis factor receptor; VEGF, vascular endothelial growth factor.

stimuli, including allergens, cigarette smoking, air pollution, and respiratory infections, particularly those of viral origin. ${ }^{64}$ Indeed, exacerbations in asthma and COPD are often triggered by common factors, including respiratory viruses during the autumn/winter months, ${ }^{65}$ gastroesophageal reflux disease, ${ }^{66}$ and also comorbidities, although the specific comorbidities differ between the two conditions. $^{33,67}$

While a smaller proportion of patients with asthma are smokers or ex-smokers than among patients with COPD,

Table 2 Clinical and pathological similarities between asthma and COPD

\begin{tabular}{lll}
\hline Feature & Asthma & COPD \\
\hline Thickened airway smooth muscle layer & Yes & Yes (minimally) \\
Inflammation involving goblet cells & Yes & Yes \\
Increased neutrophils in sputum & Yes (severe asthma) & Yes \\
Increased eosinophils in airways & Yes & Yes (steroid-sensitive COPD) \\
Increased CXC chemokine 8 & Yes (severe asthma) & Yes \\
Increased TNF & Yes (severe asthma) & Yes \\
Increased leukotriene $B_{4}$ & Yes (severe asthma) & Yes \\
Oxidative stress & Yes (severe asthma) & Yes
\end{tabular}

Notes: Data from Barnes ${ }^{52}$ and Nakawah et al. ${ }^{60}$

Abbreviation: TNF, tumor necrosis factor. 
smoking has negative consequences for both diseases in relation to morbidity, mortality, disease control, and response to medication. ${ }^{68,69}$

\section{Asthma and COPD overlap syndrome}

The recently revised GINA asthma guidelines include consensus guidance, developed in conjunction with GOLD, on the identification and differential diagnosis of ACOS. ${ }^{49}$ Characterized by moderate airflow limitation, pronounced but incomplete reversibility, and no or very little emphysema, ACOS is ill-defined and may be difficult to treat because medications have not been evaluated in ACOS-specific randomized trials. ${ }^{62}$ The prevalence of ACOS varies according to geographic region and clinical setting (primary care or specialist practice), and is believed to be high, partly because of a lack of consistent diagnosis (Figure 3). A survey of Italian patients with physician-diagnosed asthma, COPD, or ACOS revealed that among those diagnosed with asthma, 16\%-61\% also had ACOS, while for those diagnosed with COPD, 25\%-33\% also had ACOS, with the incidence varying according to age group. ${ }^{70}$

Patients with ACOS tend to be older than those with asthma, they have a significant smoking history, present with asthmatic features to their COPD, and have persistent airflow limitation. ${ }^{49,61}$ Physicians need to be able to differentiate between asthma, COPD, and ACOS so that patients receive the most appropriate treatment. For instance, the response to inhaled corticosteroids and $\beta_{2}$-agonists is superior in patients with features of both
COPD and asthma than in those only with features of COPD $;^{71}$ however, exacerbation frequency and severity is worse in the population with overlapping symptoms, although the progression in terms of $\mathrm{FEV}_{1}$ decline may be slower than in COPD. ${ }^{72,73}$ Guidelines are intended to help improve the accurate diagnosis of each condition and ensure patients receive individualized treatment. ${ }^{49,74}$ Patients with this phenotype have most likely an enhanced response to inhaled corticosteroids, owing to the presence of eosinophilic bronchial inflammation. ${ }^{75-77}$

\section{Future management of COPD: recognition of treatable traits}

COPD is a complex heterogeneous disease where assessment and management have traditionally been based on the

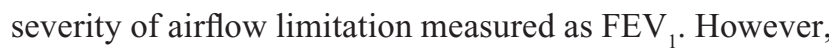
it is now recognized that $\mathrm{FEV}_{1}$ does not describe the complexity of the disease and that other factors need to be measured to fully assess this condition. More recently, the GOLD strategy document has proposed a combined assessment using three variables: symptoms, airflow limitation, and exacerbations. ${ }^{2}$ Phenotypes like frequent exacerbators, patients with predominant emphysema, and patients with overlapping characteristics of asthma and COPD warrant specific treatments. In addition, it has been proposed that in the future more variables should be added to the assessment that reflect the three domains of disease severity, activity, and impact (Figure 4$).^{78}$ For example, evaluation

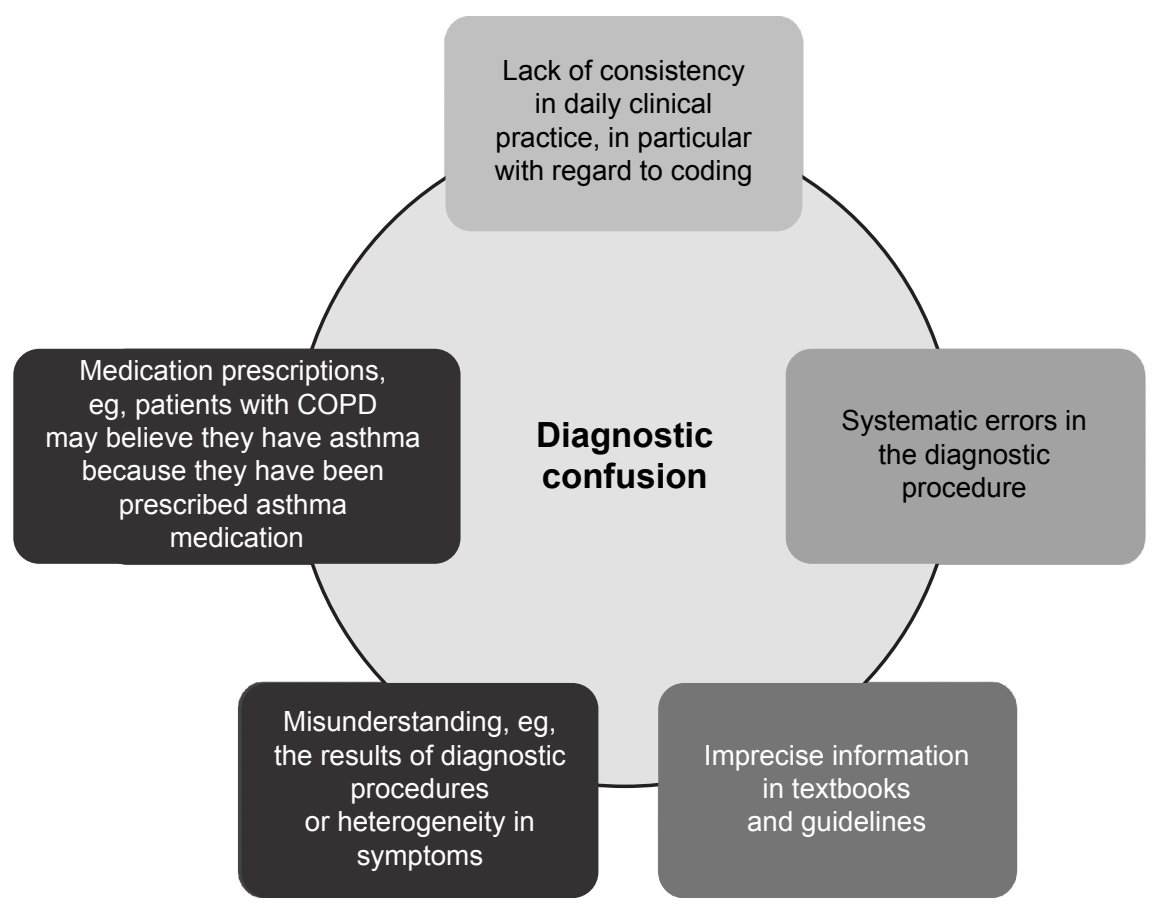

Figure 3 Potential reasons for the high prevalence of overlap between COPD and asthma. 

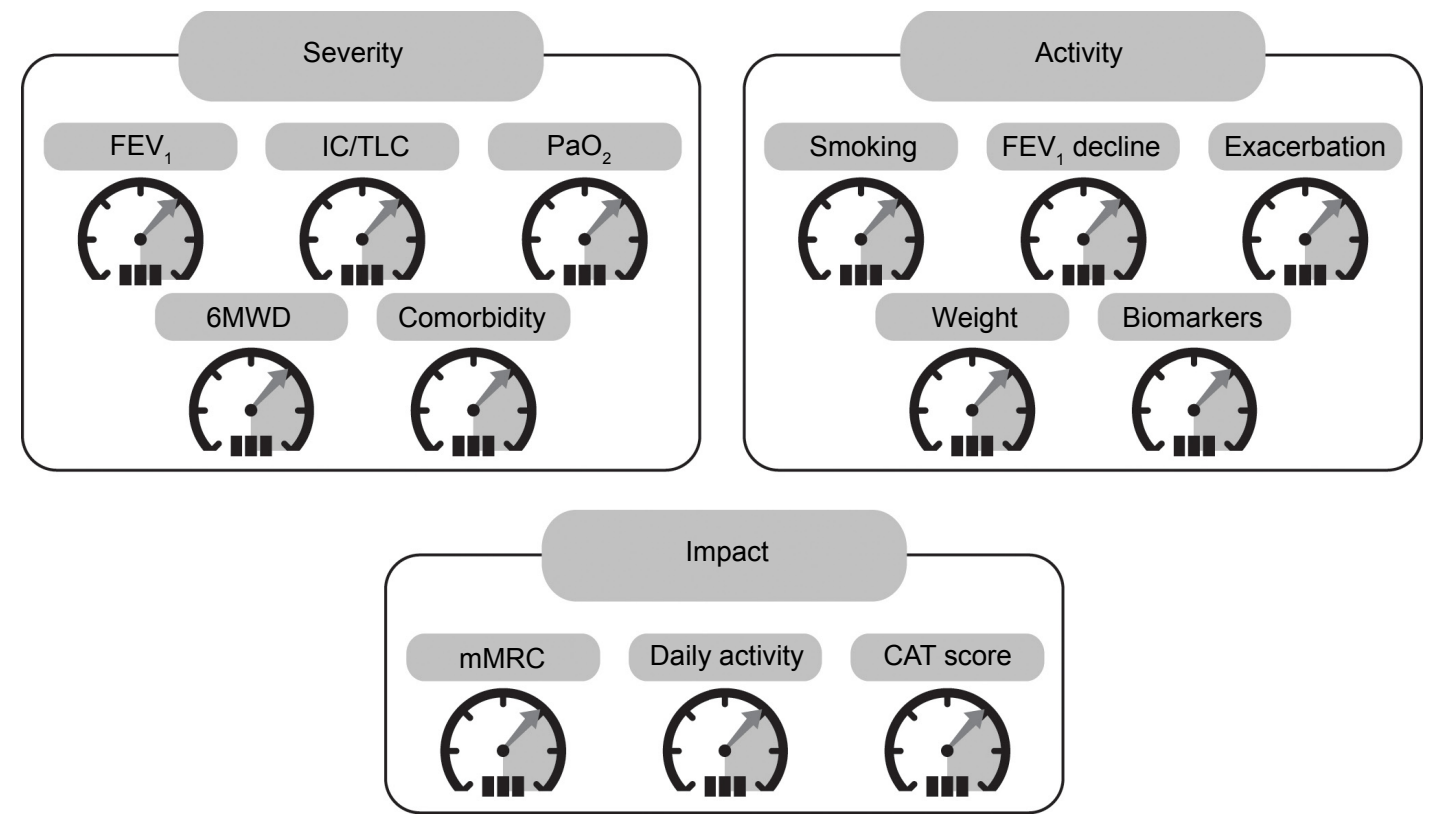

Figure 4 Proposal for a COPD assessment control panel of variables that relate to three domains of the disease - severity, activity, and impact.

Notes: Adapted by permission from BMJ Publishing Group Ltd. Thorax. Agusti A, MacNee W. The COPD control panel: towards personalised medicine in COPD. Volume 68(7), pages 687-690. Copyright (C2013.78

Abbreviations: 6MWD, 6-minute walk distance; CAT, COPD Assessment Test; IC/TLC, inspiratory to total lung capacity ratio; mMRC, modified Medical Research Council Dyspnea Scale; $\mathrm{PaO}_{2}$, arterial oxygen pressure.

of the disease severity domain could include assessment of arterial oxygen pressure, the IC/TLC ratio, and 6MWD in addition to more standard measures such as $\mathrm{FEV}_{1} \cdot{ }^{78}$ Each of the domains will provide information on different aspects of the disease with a potential influence on clinical outcomes or potentially requiring specific targeted therapy, and provides a route towards personalized medicine for COPD.

Thus, regardless of the diagnostic labeling, which may change over time, the authors of this review believe that patients with COPD should be assessed beyond $\mathrm{FEV}_{1}$ and treated according to their individual clinical characteristics. Although this approach introduces complexity into the treatment algorithm and departs from the "one size fits all" treatment based on the level of $\mathrm{FEV}_{1}$, it is likely to improve the clinical outcomes in most of the patients with the label of COPD.

\section{Acknowledgments}

Medical writing support was provided by Rhian Harper Owen on behalf of Complete Medical Communications. Medical writing support for this review was funded by Almirall S.A., Barcelona, Spain.

\section{Disclosure}

PL has previously received fees and honoraria for speaking, board membership, and educational materials from Almirall, AstraZeneca, Boehringer Ingelheim, Chiesi, GlaxoSmithKline,
Mundipharma, Novartis, Nycomed, Pfizer, and TEVA, and has received research grants from AstraZeneca, GlaxoSmithKline, Pfizer, Boehringer Ingelheim, Novartis, and Almirall. DMH has previously received honoraria for speaking and consultancy from Almirall, AstraZeneca, Boehringer Ingelheim, Chiesi, GlaxoSmithKline, InterMune, Napp, Novartis, Nycomed, MSD, and Pfizer. DEO has previously received speaker fees from Almirall. WM has previously received fees or honoraria for speaking or consultancy from GlaxoSmithKline, Boehringer Ingelheim, Novartis, Pfizer, Kyorin, and Almirall, and has received research grants or undertaken clinical trials for Pfizer, GlaxoSmithKline, Kamada, and Janssen. The authors report no other conflicts of interest in this work.

\section{References}

1. Han MK, Agusti A, Calverley PM, et al. Chronic obstructive pulmonary disease phenotypes: the future of COPD. Am J Respir Crit Care Med. 2010;182(5):598-604.

2. Global Initiative for Chronic Obstructive Lung Disease. Global strategy for the diagnosis, management, and prevention of chronic obstructive pulmonary disease [updated 2015]. Available from: http://www.goldcopd. org/uploads/users/files/GOLD_Report_2015_Feb18.pdf. Accessed March 30, 2015.

3. van der Molen T, Miravitlles M, Kocks JW. COPD management: role of symptom assessment in routine clinical practice. Int J Chron Obstruct Pulmon Dis. 2013;8:461-471.

4. Arne M, Emtner M, Janson S, Wilde-Larsson B. COPD patients perspectives at the time of diagnosis: a qualitative study. Prim Care Respir J. 2007;16(4):215-221. 
5. Mannino DM, Sonia BA, Vollmer WM. Chronic obstructive pulmonary disease in the older adult: what defines abnormal lung function? Thorax. 2007;62(3):237-241.

6. Price DB, Yawn BP, Jones RC. Improving the differential diagnosis of chronic obstructive pulmonary disease in primary care. Mayo Clin Proc. 2010;85(12):1122-1129.

7. Puente-Maestu L, Stringer WW. Hyperinflation and its management in COPD. Int J Chron Obstruct Pulmon Dis. 2006;1(4):381-400.

8. Deesomchok A, Webb KA, Forkert L, et al. Lung hyperinflation and its reversibility in patients with airway obstruction of varying severity. COPD. 2010;7(6):428-437.

9. Casanova C, Cote C, de Torres JP, et al. Inspiratory-to-total lung capacity ratio predicts mortality in patients with chronic obstructive pulmonary disease. Am J Respir Crit Care Med. 2005;171(6):591-597.

10. O’Donnell DE, Guenette JA, Maltais F, Webb KA. Decline of resting inspiratory capacity in COPD: the impact on breathing pattern, dyspnea, and ventilatory capacity during exercise. Chest. 2012;141(3): 753-762.

11. Agusti A, Calverley PM, Celli B, et al. Characterisation of COPD heterogeneity in the ECLIPSE cohort. Respir Res. 2010;11:122.

12. Pinto-Plata VM, Cote C, Cabral H, Taylor J, Celli BR. The 6-min walk distance: change over time and value as a predictor of survival in severe COPD. Eur Respir J. 2004;23(1):28-33.

13. Polkey MI, Spruit MA, Edwards LD, et al. Six-minute-walk test in chronic obstructive pulmonary disease: minimal clinically important difference for death or hospitalization. Am J Respir Crit Care Med. 2013; 187(4):382-386

14. Borel B, Provencher S, Saey D, Maltais F. Responsiveness of various exercise-testing protocols to therapeutic interventions in COPD. Pulm Med. 2013;2013:410748.

15. Tojo N, Ichioka M, Chida M, Miyazato I, Yoshizawa Y, Miyasaka N. Pulmonary exercise testing predicts prognosis in patients with chronic obstructive pulmonary disease. Intern Med. 2005;44(1):20-25.

16. Castaldi PJ, San Jose ER, Mendoza CS, et al. Distinct quantitative computed tomography emphysema patterns are associated with physiology and function in smokers. Am J Respir Crit Care Med. 2013;188(9): 1083-1090.

17. Coxson HO, Dirksen A, Edwards LD, et al. The presence and progression of emphysema in COPD as determined by CT scanning and biomarker expression: a prospective analysis from the ECLIPSE study. Lancet Respir Med. 2013;1(2):129-136.

18. Coxson HO, Leipsic J, Parraga G, Sin DD. Using pulmonary imaging to move chronic obstructive pulmonary disease beyond $\mathrm{FEV}_{1}$. Am J Respir Crit Care Med. 2014;190(2):135-144.

19. Pare PD, Nagano T, Coxson HO. Airway imaging in disease: gimmick or useful tool? J Appl Physiol (1985). 2012;113(4):636-646.

20. Vestbo J, Edwards LD, Scanlon PD, et al. Changes in forced expiratory volume in 1 second over time in COPD. N Engl J Med. 2011;365(13) 1184-1192.

21. Han MK, Kazerooni EA, Lynch DA, et al. Chronic obstructive pulmonary disease exacerbations in the COPDGene study: associated radiologic phenotypes. Radiology. 2011;261(1):274-282.

22. Mair G, Miller JJ, McAllister D, et al. Computed tomographic emphysema distribution: relationship to clinical features in a cohort of smokers. Eur Respir J. 2009;33(3):536-542.

23. Mair G, Maclay J, Miller JJ, et al. Airway dimensions in COPD: relationships with clinical variables. Respir Med. 2010;104(11):1683-1690.

24. Fishman A, Martinez F, Naunheim K, et al. A randomized trial comparing lung-volume-reduction surgery with medical therapy for severe emphysema. N Engl J Med. 2003;348(21):2059-2073.

25. Williams MC, Murchison JT, Edwards LD, et al. Coronary artery calcification is increased in patients with COPD and associated with increased morbidity and mortality. Thorax. 2014;69(8): 718-723.

26. Hersh CP, Jacobson FL, Gill R, Silverman EK. Computed tomography phenotypes in severe, early-onset chronic obstructive pulmonary disease. COPD. 2007;4(4):331-337.
27. Vestbo J, Agusti A, Wouters EF, et al. Should we view chronic obstructive pulmonary disease differently after ECLIPSE? A clinical perspective from the study team. Am J Respir Crit Care Med. 2014;189(9):1022-1030.

28. Stoller JK, Aboussouan LS. A review of alpha1-antitrypsin deficiency. Am J Respir Crit Care Med. 2012;185(3):246-259.

29. Miravitlles M, Calle M, Soler-Cataluna JJ. Clinical phenotypes of COPD: identification, definition and implications for guidelines. Arch Bronconeumol. 2012;48(3):86-98.

30. Hurst JR, Vestbo J, Anzueto A, et al. Susceptibility to exacerbation in chronic obstructive pulmonary disease. $N$ Engl J Med. 2010;363: 1128-1138.

31. Albert RK, Connett J, Bailey WC, et al. Azithromycin for prevention of exacerbations of COPD. N Engl J Med. 2011;365(8):689-698.

32. Lee SJ, Lee SH, Kim YE, et al. Clinical features according to the frequency of acute exacerbation in COPD. Tuberc Respir Dis (Seoul). 2012;72(4):367-373.

33. Wedzicha JA, Brill SE, Allinson JP, Donaldson GC. Mechanisms and impact of the frequent exacerbator phenotype in chronic obstructive pulmonary disease. BMC Med. 2013;11:181.

34. O’Donnell DE, Gebke KB. Activity restriction in mild COPD: a challenging clinical problem. Int J Chron Obstruct Pulmon Dis. 2014;9:577-588

35. Raghavan N, Ora J, Webb KA, O’Donnell DE. "Mild” chronic obstructive pulmonary disease - is there a case for earlier treatment? Annals of Respiratory Medicine. 2010;1(1):23-30.

36. Nishimura M, Makita H, Nagai K, et al. Annual change in pulmonary function and clinical phenotype in chronic obstructive pulmonary disease. Am J Respir Crit Care Med. 2012;185(1):44-52.

37. Burgel PR, Paillasseur JL, Peene B, et al. Two distinct chronic obstructive pulmonary disease (COPD) phenotypes are associated with high risk of mortality. PLoS One. 2012;7(12):e51048.

38. Cavailles A, Brinchault-Rabin G, Dixmier A, et al. Comorbidities of COPD. Eur Respir Rev. 2013;22(130):454-475.

39. Agusti A, Edwards LD, Rennard SI, et al. Persistent systemic inflammation is associated with poor clinical outcomes in COPD: a novel phenotype. PLoS One. 2012;7(5):e37483.

40. Thomsen M, Dahl M, Lange P, Vestbo J, Nordestgaard BG. Inflammatory biomarkers and comorbidities in chronic obstructive pulmonary disease. Am J Respir Crit Care Med. 2012;186(10):982-988.

41. Kim V, Davey A, Comellas AP, et al. Clinical and computed tomographic predictors of chronic bronchitis in COPD: a cross sectional analysis of the COPDGene study. Respir Res. 2014;15:52.

42. Izquierdo-Alonso JL, Rodriguez-Gonzalezmoro JM, de Lucas-Ramos P, et al. Prevalence and characteristics of three clinical phenotypes of chronic obstructive pulmonary disease (COPD). Respir Med. 2013; 107(5):724-731.

43. Fuschillo S, Martucci M, Donner CF, Balzano G. Airway bacterial colonization: the missing link between COPD and cardiovascular events? Respir Med. 2012;106(7):915-923.

44. Kiri VA, Soriano J, Visick G, Fabbri L. Recent trends in lung cancer and its association with COPD: an analysis using the UK GP Research Database. Prim Care Respir J. 2010;19(1):57-61.

45. Burger CD. Pulmonary hypertension in COPD: a review and consideration of the role of arterial vasodilators. COPD. 2009;6(2):137-144.

46. Hurdman J, Condliffe R, Elliot CA, et al. Pulmonary hypertension in COPD: results from the ASPIRE registry. Eur Respir J. 2013;41(6): 1292-1301.

47. Adir Y, Shachner R, Amir O, Humbert M. Severe pulmonary hypertension associated with emphysema: a new phenotype? Chest. 2012;142(6) 1654-1658.

48. Thomsen M, Nordestgaard BG, Vestbo J, Lange P. Characteristics and outcomes of chronic obstructive pulmonary disease in never smokers in Denmark: a prospective population study. Lancet Respir Med. 2013; 1(7):543-550.

49. Global Initiative for Asthma. Global Strategy for Asthma Management and Prevention [updated 2015 Apr]. Available from: www.ginasthma. org. Accessed May 1, 2015. 
50. Vestbo J. Clinical assessment of COPD. In: Hanania NA, Sharafkhaneh A, editors. COPD: A Guide to Diagnosis and Clinical Management, Respiratory Medicine. Berlin, Germany: Springer, LLC; 2011.

51. Bateman ED, Hurd SS, Barnes PJ, et al. Global strategy for asthma management and prevention: GINA executive summary. Eur Respir J. 2008;31(1):143-178.

52. Barnes PJ. Immunology of asthma and chronic obstructive pulmonary disease. Nat Rev Immunol. 2008;8(3):183-192.

53. Bafadhel M, McCormick M, Saha S, et al. Profiling of sputum inflammatory mediators in asthma and chronic obstructive pulmonary disease. Respiration. 2012;83(1):36-44.

54. Shimizu K, Hasegawa M, Makita H, Nasuhara Y, Konno S, Nishimura M. Comparison of airway remodelling assessed by computed tomography in asthma and COPD. Respir Med. 2011;105(9):1275-1283.

55. James AL, Palmer LJ, Kicic E, et al. Decline in lung function in the Busselton Health Study: the effects of asthma and cigarette smoking. Am J Respir Crit Care Med. 2005;171(2):109-114.

56. Wang X, Mensinga TT, Schouten JP, Rijcken B, Weiss ST. Determinants of maximally attained level of pulmonary function. Am J Respir Crit Care Med. 2004;169(8):941-949.

57. Haldar P, Pavord ID, Shaw DE, et al. Cluster analysis and clinical asthma phenotypes. Am J Respir Crit Care Med. 2008;178(3):218-224.

58. Howrylak JA, Fuhlbrigge AL, Strunk RC, Zeiger RS, Weiss ST, Raby BA. Classification of childhood asthma phenotypes and long-term clinical responses to inhaled anti-inflammatory medications. J Allergy Clin Immunol. 2014;133(5):1289-1300.

59. Agusti A. The path to personalised medicine in COPD. Thorax. 2014; 69(9):857-864.

60. Nakawah MO, Hawkins C, Barbandi F. Asthma, chronic obstructive pulmonary disease (COPD), and the overlap syndrome. J Am Board Fam Med. 2013;26(4):470-477.

61. Zeki AA, Schivo M, Chan A, Albertson TE, Louie S. The asthma-COPD overlap syndrome: a common clinical problem in the elderly. J Allergy (Cairo). 2011;2011:861926

62. Shaya FT, Dongyi D, Akazawa MO, et al. Burden of concomitant asthma and COPD in a Medicaid population. Chest. 2008;134(1):14-19.

63. Soriano JB, Davis KJ, Coleman B, Visick G, Mannino D, Pride NB. The proportional Venn diagram of obstructive lung disease: two approximations from the United States and the United Kingdom. Chest. $2003 ; 124(2): 474-481$

64. Meyers DA, Larj MJ, Lange L. Genetics of asthma and COPD. Similar results for different phenotypes. Chest. 2004;126(2 Suppl): $105 \mathrm{~S}-110 \mathrm{~S}$.
65. Hershenson MB. Rhinovirus-induced exacerbations of asthma and COPD. Scientifica (Cairo). 2013;2013:405876.

66. Gaude GS. Pulmonary manifestations of gastroesophageal reflux disease. Ann Thorac Med. 2009;4(3):115-123.

67. Boulet LP. Influence of comorbid conditions on asthma. Eur Respir J. 2009;33(4):897-906.

68. Chalmers GW, MacLeod KJ, Little SA, Thomson LJ, McSharry CP, Thomson NC. Influence of cigarette smoking on inhaled corticosteroid treatment in mild asthma. Thorax. 2002;57(3):226-230.

69. Colak Y, Afzal S, Nordestgaard BG, Lange P. Characteristics and prognosis of never smokers and smokers with asthma in the Copenhagen general population study: a prospective cohort study. Am J Respir Crit Care Med. 2015;192(2):172-181.

70. de Marco R, Pesce G, Marcon A, et al. The coexistence of asthma and chronic obstructive pulmonary disease (COPD): prevalence and risk factors in young, middle-aged and elderly people from the general population. PLoS One. 2013;8(5):e62985.

71. Kitaguchi Y, Komatsu Y, Fujimoto K, Hanaoka M, Kubo K. Sputum eosinophilia can predict responsiveness to inhaled corticosteroid treatment in patients with overlap syndrome of COPD and asthma. Int $J$ Chron Obstruct Pulmon Dis. 2012;7:283-289.

72. Hardin M, Silverman EK, Barr RG, et al. The clinical features of the overlap between COPD and asthma. Respir Res. 2011;12:127.

73. Fu JJ, Gibson PG, Simpson JL, McDonald VM. Longitudinal changes in clinical outcomes in older patients with asthma, COPD and asthmaCOPD overlap syndrome. Respiration. 2014;87(1):63-74.

74. Global Initiative for Chronic Obstructive Lung Disease. Global strategy for the diagnosis, management and prevention of chronic obstructive pulmonary disease [updated 2014 Jan]. Available from: http://www. goldcopd.com/guidelines-global-strategy-for-diagnosis-management. html. Accessed November 12, 2014.

75. Afshar K. Treatment based on phenotypic variants in chronic obstructive pulmonary disease. J Pulm Respir Med. 2013;3:e128.

76. Brightling CE, Monteiro W, Ward R, et al. Sputum eosinophilia and shortterm response to prednisolone in chronic obstructive pulmonary disease: a randomised controlled trial. Lancet. 2000;356(9240):1480-1485.

77. Dummer JF, Epton MJ, Cowan JO, et al. Predicting corticosteroid response in chronic obstructive pulmonary disease using exhaled nitric oxide. Am J Respir Crit Care Med. 2009;180(9):846-852.

78. Agusti A, MacNee W. The COPD control panel: towards personalised medicine in COPD. Thorax. 2013;68(7):687-690.

79. O'Donnell DE, Laveneziana P. The clinical importance of dynamic lung hyperinflation in COPD. COPD. 2006;3(4):219-232.
International Journal of COPD

\section{Publish your work in this journal}

The International Journal of COPD is an international, peer-reviewed journal of therapeutics and pharmacology focusing on concise rapid reporting of clinical studies and reviews in COPD. Special focus is given to the pathophysiological processes underlying the disease, intervention programs, patient focused education, and self management protocols.

\section{Dovepress}

This journal is indexed on PubMed Central, MedLine and CAS. The manuscript management system is completely online and includes a very quick and fair peer-review system, which is all easy to use. Visit http://www.dovepress.com/testimonials.php to read real quotes from published authors. 